\title{
Projecting populations for major Pacific Island countries with and without COVID-19: pro-active insights for population policy
}

\author{
Sumeet Lal ${ }^{1} \cdot$ Rup Singh $^{1} \cdot$ Ronal Chand $^{1} \cdot$ Arvind Patel $^{1}$. \\ Devendra Kumar Jain ${ }^{1}$
}

Accepted: 12 December 2020 / Published online: 28 September 2021

(c) The Author(s), under exclusive licence to Springer Nature B.V. 2021

\begin{abstract}
The paper projects aggregate populations of six Pacific Island countries in both preand post-COVID19 scenarios using a Cohort Component Method for the period 2020-2060. It uses baseline indicators resembling China and Italy's experiences and finds that Pacific countries could experience a fatality rate between 5 and $20 \%$ due to the pandemic. It also finds that most Pacific Island countries would experience higher fatalities in the older age groups, consistent with what is being witnessed in other countries around the world. The analysis also shows that while the risk escalates for people over 50 years onward in all other sample countries, in Fiji, those in the age range of 60 years or more are at higher risk. The findings also indicate that for all countries, the fatality rate for 80 years and older is about $50 \%$. The population projections show that Fiji will be most impacted, while others will experience around $2 \%$ initial population decline. The convergence to baseline is found to be slow (except for Tonga) in most Pacific countries. Consequently, the paper suggests a cautious approach in dealing with the current crisis.
\end{abstract}

Keywords South Pacific population projection - Cohort component model · Population policy $\cdot$ COVID-19 Impact in the South Pacific

JEL Classification $\mathrm{J} 11 \cdot \mathrm{J} 14 \cdot \mathrm{J} 18$

Devendra Kumar Jain

dkumar54@gmail.com

1 School of Accounting, Finance \& Economics, The University of the South Pacific, Suva, Fiji 


\section{Introduction}

The economies of the Pacific region are small and vulnerable, and therefore face multiple socio-economic challenges (ADB, 2017; The United Nations, 2019; Congdon, 2014; Tisdell, 2014). Having small populations also undermines any scale effects, innovations and much of the needed economic growth (Jones, 1995). But Pacific populations also suffer from several demographic setbacks. These are constant emigration (Campbell \& Warrick, 2014), declining birth rates (Narsey, et al., 2009) and rising death rates (United Nations Population Fund, 2014). The latter is strongly related to health risks resulting from non-communicable diseases (mostly diabetes, hypertension, and respiratory problems), others are lifestyle-related such as obesity and heart diseases, etc. (Hou et al., 2016) but also due to the sudden outbreak of pandemics and other natural disasters. The Region's average out-migration rate stabilised to $8.5 \%$ per annum in 2016 (Secretariate of the Pacific Community, 2016), with Pacific people emigrating mainly to Australia, New Zealand, and the USA. The region's fertility rate averages 3.5 births per woman (The World Bank, 2017) due to factors like income growth, educated young population, high cost of living and delay in marriage (Gani, 1999; Lal \& Singh, 2019).

This paper projects populations of six Pacific Island Countries (Fiji, Samoa, the Solomon Islands, Vanuatu, Tonga, and PNG) using country-specific population variants and the Cohort Component Method (CCM) over the period 2020-2060. ${ }^{1}$ Our estimates are compared with that of the United Nations Population Division (UNPD, 2014) and the Secretariat of the Pacific Community's (SPC, 2016) predictions. More interestingly, this paper generates ex-ante alternative post COVID19 population scenarios using experiences of China and Italy in the pandemic as a backdrop. China is selected because of its success in containing the virus while we consider Italy as the worst case of COVID $19 .{ }^{2}$ We use the rates of China as the minimum and those of Italy as maximum values of fatality indicators in our calculations. Although our benchmark countries are large and diverse, given the absence of reliable local indicators, they do provide workable assumptions and data for modelling. However, there are two caveats. First, most of the Pacific countries have not yet been fully exposed to the virus, but they are not immune to the pandemic either. As such, our results are pre-emptive. Second, actual fatality rates are either very low or unknown for these countries.

Despite low COVID19 related infections and mortality in the Pacific, the countries still share exclusive challenges-they are small, geographically isolated, vulnerable to acute environmental or health shocks and unable to benefit from potential scale effects. If fully exposed to COVID19, the majority of the islands could be devastated in a very short period due to low populations and weaker health services. In

\footnotetext{
${ }^{1}$ The selection of countries is based on the following: They comprise about $97 \%$ of the region's population and $99 \%$ of total land area. These countries also suffer from shortage of labour and low economic productivity.

${ }^{2}$ More recent international experiences put the USA in the forefront. However, at the time of analysis, only limited data was available.
} 
PNG, for example, over $80 \%$ of the population live in rural areas where health facilities are inadequate. Health centres frequently run out of supplies and just recently, 4000 nurses went on strike due to insufficient personal protective equipment (PPE) provided to them (Ellis, 2020). The fact is that basic services and accessibility to vital care or fully equipped hospitals is impossible in outer islands and rural areas across the Pacific Island Countries (PICs). The Guardian ${ }^{3}$ reports that Vanuatu has only two ventilators for a population of 300,000 people. Due to limited biotechnological resources, only a few Pacific nations can effectively test for COVID19. Many of the processing samples are being sent to Australia, New Zealand, or the United States. The lag in testing and results may further compound the situation.

Communicable and non-communicable diseases are troublesome in the Pacific. For example, the Pacific has the world's highest levels of Type 2 diabetes and exceptionally high levels of obesity. ${ }^{4}$ Therefore, any chronic conditions will likely set up a death path for those people exposed to the virus. Further, Pacific culture mostly evolves around close-knit extended families which can enhance the risk of community-based transmissions. Social distancing may have worked in large, industrialised nations but has failed to make significant impacts in the Pacific diaspora. Thus, for all these reasons, we chose PICs for our sample countries. The paper has a high potential for future research and follow- up studies.

There is evidence that COVID19 is already impacting most of these economies either directly or indirectly, and its combined effect on the Pacific population is likely to be significant. Thus, the use of benchmark indicators (which are relatively high but standardised with individual country contexts) is valid. We also note that each of our sample countries' capacities, resources, and medical services are limited. Thus, a timely population projection would give a better understanding of the looming calamity because of the communal style of living, under-resourced governments, fragile medical services, and the local culture that lacks seriousness in heeding warnings and can be a good breeding ground for the virus. But in the absence of real-time local data, we depend on indicative global parameters and analytical models. As such, our work is exploratory.

The rest of the paper is structured as follows: the following section is a survey of related literature on population projection, followed by "Conceptual Framework" section which explains the methodology adopted in our work. "Results: pre-COVID population projections (2020-2050)" section presents the findings and compares them with the UNPD's and SPC's outlook for the pre-COVID19 scenario. In "Potential impact of COVID19"section, we re-project the populations of the six countries in alternative post-COVID19 scenarios. Unfortunately, we cannot compare these estimates with others because to the best of our knowledge, there are not any such

\footnotetext{
3 The Guardian. (2020, April 07). 'If it comes, it will be a disaster': life in one of the only countries without coronavirus. Retrieved from The Guardian: https://www.theguardian.com/world/2020/apr/08/ifit-comes-it-will-be-a-disaster-life-in-vanuatu-one-of-the-only-countries-without-coronavirus.

$445-65 \%$ of the adults are obese in countries such as Nauru, Cook Islands, Palau, Marshall Islands, Tuvalu, Niue Tonga, Samoa, Kiribati, and Federal States of Micronesia- see https://obesity.procon.org/ global-obesity-levels/.
} 
projections available. The final section concludes the paper with limitations and recommendations for population policy.

\section{Survey of the literature}

Population projection and planning are important for any country, but they must be based on credible information about how the essential demographic variables are expected to change in the future. A range of assumptions generate alternative projections but the most appropriate one is used for population planning (Wilson \& Rees, 2005).It is difficult to have complete and accurate information because of the uncertainty in the future values of the variables and their trends. This makes population projection difficult and often controversial (Keilman, 1998). Since population momentum (resulting from large segments of the young population) still exists in many countries (UNPD, 2014; Li \& Tuljapurkar, 1999), researchers tend to produce high-quality short-medium term projections which are more realistic. However, as the momentum diminishes, future demographic changes are exposed to much uncertainty, but the population tends to be strongly influenced by fertility, mortality, and migration rates (Blue and Espenshade, 2011). Thus, these three variables are essential to population projections.

Researchers have developed ways to deal with these uncertainties. One is to compile a list of assumptions regarding the future proximate behaviour of variables because with valid assumptions, better approximations are possible (Dion, 2012). A well-accepted method is to use projection variants with a range of plausible values allowing for qualitative description to produce more insightful results (Beer, 2000; Heilig, et al., 2010). Population projections also improved by adopting methods with multiple processes of demographic change that affect population through appropriate groupings, which can vary at different intensities (Gans, 1999). Despite the limitations, the UNPD used the Cohort Component Method (CCM) to project the USA's population, and more recently developed Bayesian Probabilistic Projections for all countries from 2015 to 2100 including those of the Pacific, (Raftery et al., 2014). They use a Total Fatality Rate (TFR) of 2.0, consistent with Australia, France, New Zealand, and the USA as these are the metropolitan focal points and have completed their demographic transitions. The CCM method has also been used to predict the USA's population from 2017 to 2060 under three alternative migration scenarios mainly to examine how the USA's population would change if future patterns of immigration differ radically from the historical trends. The 2017 projections for the USA have been disaggregated by age, sex, race, and origin (Johnson, 2020) but this could not have been possible without the input of high-quality microdata.

Similarly, the Australian Bureau of Statistics used the CCM approach to produce population projections from 2018 to 2066 for all of Australia, its different states, territories, and capital cities. As future levels of fertility, mortality, overseas migration, and internal migration are unpredictable, two or more assumptions have been made for each of these components; and the projections have been produced for all combinations of assumptions. These are intended to illustrate a range of possible future outcomes, although there can be no certainty that any particular outcome will 
be realised, or that those future outcomes will necessarily fall within those ranges. The combination of assumptions created 54 sets of population projections (Australian Bureau of Statistics, 2018), producing useful information about possible futures (Table 1).

Statistics New Zealand also did national population projections from 2016 to 2068. They used probabilistic population projections to determine estimates of uncertainty produced by combining 2,000 simulations of assumptions. These simulations can be summarised by percentiles, which indicate the probability that the actual result is lower than the percentile (Stats NZ, 2017). The SPC's (2016) fiveyear age-interval population projections (2016-2050) are derived using the CCM approach. Their results are similar to ours (details later) but have not been revised since. To the best of our knowledge, there are no other such projections for countries of the Pacific region.

Given the task at hand, we use the CCM approach, which fits small populations (Keyfitz, 1972) quite well in the short-medium term time interval. Internationally, apart from the UNPD (initially), the CCM method has been used by the USA's National Center for Education Statistics (2014), the Ministry of Education (2009), Kodiko (2011), (Wilson, A Review of Sub-Regional Population Projection Methods, 2011) and (George, et al., 2004). The attractive features of CCM are that it conforms to theory by incorporating features of demographic processes. Second, it is quite precise (Kamunya, 2010) with data demands manageable for small economies. Besides, due to advancements in estimation software and methodology, human error is minimized, and projections are verifiable (Murdock et al, 1991). Further, the CCM fits into different scenarios of socio-economic and policy settings.

\section{Conceptual framework}

The routines in CCM can be summarised as follows: First, the base population is established by computing the death and net migration effects within each of the age-sex cohorts. Extrapolation of existing data has generated future trends in the variables using the SPECTRUM software (Futures Group International, 2005). The assumed age-specific fertility rates are applied to women of childbearing years (15 to 49 years) to generate new birth cohorts. In the estimation process, this procedure is continually repeated every year until the final forecast period is reached (Fig. 1).

As in other forecasting exercises, assumptions of population variants can be combined with the other principal assumptions of mortality and migration (Sawyer \& Bassarsky, 2016). ${ }^{5}$ Our sample countries (in this paper) are all intermediate fertility

\footnotetext{
5 The variants normally used for population projection are: (1) Medium (Standard) which assumes each country's fertility rate will converge to replacement level of 2.1 child per woman. (ii) Constant variant assumes that fertility remains constant to the assumed values for start of projection period. (iii) High and Low Variant is where fertility is assumed to be 0.5 above and 0.5 below the fertility projected in the medium-term (iv) Instant Replacement Variant sets a fertility level necessary to ensure the population can replace itself in the longer term if mortality rates are fixed and migration is absent, and by ensuring that the net reproductive rate is 1 at the start of the first projection period.
} 


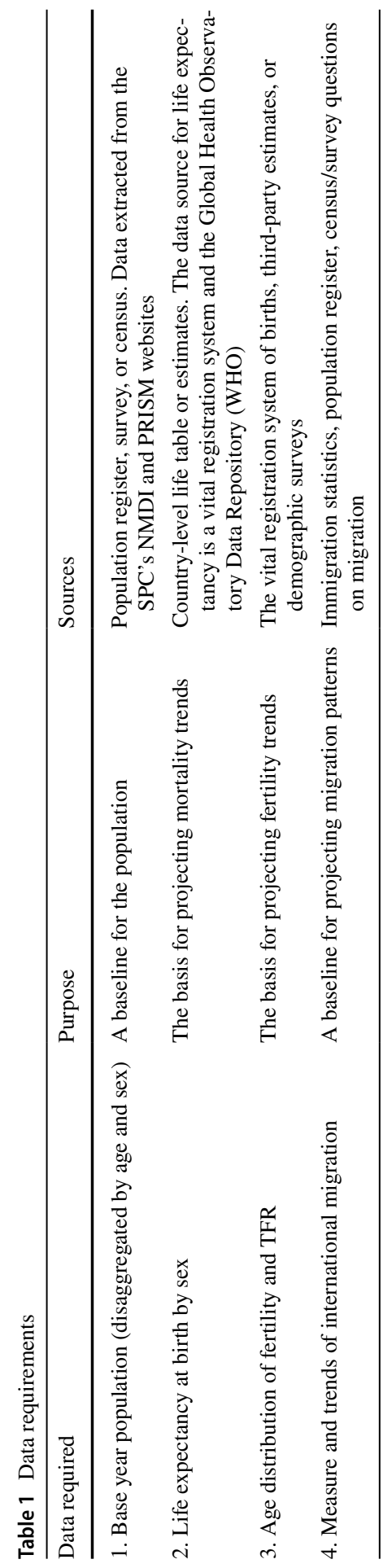




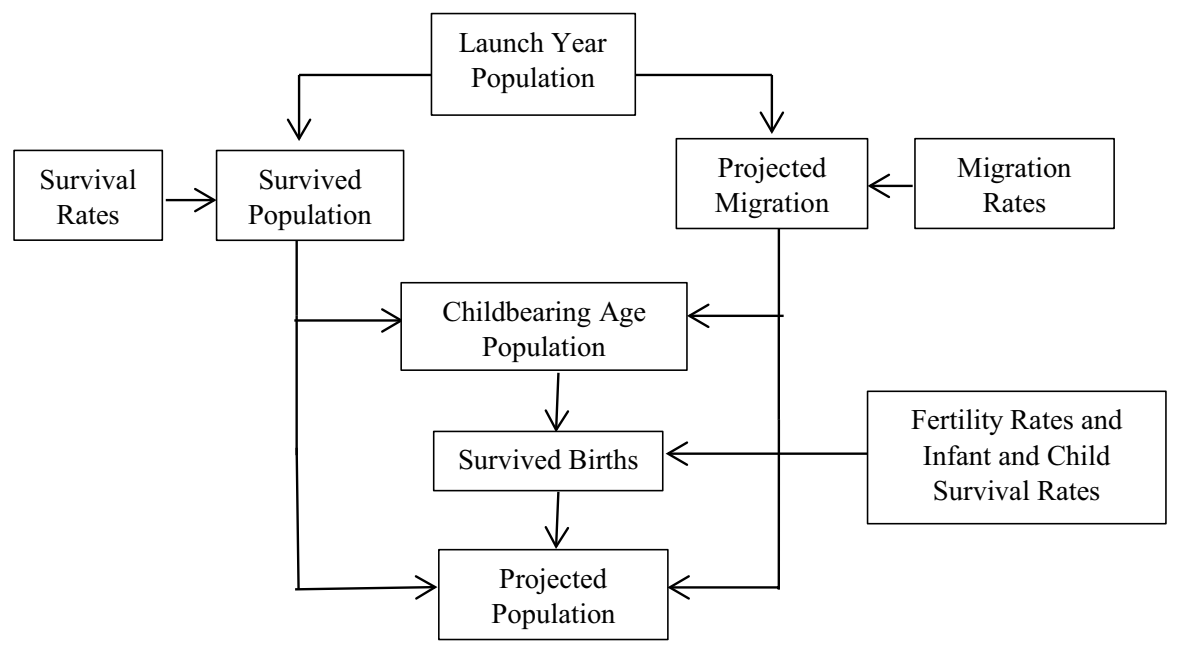

Fig. 1 Conceptual framework of cohort-component model. Source: Adapted from (Smith et al., 2001)

countries as the United Nations believes that they will have a TFR between 2.1 to 5 children per woman. Fertility rates in these countries are expected to fall below replacement level (Department of Economic and Social Affairs, 2002). By 2050, close to 80\% of the world's population, as well as $75 \%$ of developing countries' population, will be below replacement level fertility. Until recently, demographers thought that developing countries that were facing substantial fertility decline would converge to replacement level fertility and stay constant afterwards, signalling the end of the demographic transition (Morgan, 2003). Hence, there is a clear case for medium variant assumptions for the Pacific. Also, the world is converging towards low fertility rates and the UNPD (which projects populations for 193 countries by age and sex) also applies a medium variant as the likely future scenario (Samir, et al., 2010).

\section{Basic structure of cohort component model}

Choi (2010) provides the basic cohort component equation which could be modified to take account of context-specific projections. The model with the key population parameters is represented in Eq. (1).

$$
P O P_{i t}=P O P_{i t_{0}}+\left[B T_{i t-t_{0}}-D T_{i t-t_{0}}\right]+\left[M I_{i t-t_{0}}-M O_{i t-t_{0}}\right]
$$

where $P O P_{i t}$ is the projected population of a country (i) at time t, $B T_{i t-t_{0}}$ represents birth rates between the projection intervals in the country (i), similarly $D T_{i t-t_{0}}$ is relative death rates in the country (i) over the estimation interval, $\left(M I_{i t-t_{0}}-M O_{i t-t_{0}}\right)$ is net migration in the country (i) during the period. In our post-COVID19 projections, $P O P_{i t_{0}}$ is the revised base year (2020) population with estimated age-specific potential impacts of COVID19 in each country (i)—details later. The actual 
projection model embedded in the estimation software (SPECTRUM V5.761) uses an iterative procedure with robust algorithms to derive optimising solutions. There are alternative in-built packages in SPECTRUM, options for variations in the input of assumptions, and target setting options in the software as well.

\section{Key assumptions}

The projections in this paper are based on the following assumptions:

(a) Baseline population compromises males and females divided by age group as of 1st July 2019.

(b) Fertility rates take two scenarios (i) they decline over the next projection period (high growth projection) consistent with rates in developed countries and stay constant at this rate (ii) they equal age-specific rates where the TFR remains constant throughout the projection period. Data sources are the World Bank and SPC's PRISM website.

(c) Mortality depends on life expectancy and is disaggregated by gender.

(d) Net International Migration is assumed to be low and static, except where required.

(e) Sex-Ratio is assumed to be unchanged for all countries until the final year (2060).

(f) In the post-COVID19 projections, the baseline population is shocked by expected increases in age-specific mortality.

The exact time (in calendar years) by which countries of the Pacific will converge to their replacement level fertility level is in Gubhaju and Moriki (2003). These are 2020-2025 (Fiji), 2035-2040 (Tonga and Vanuatu), and 2040-2045 (Samoa, Solomon Islands, and the PNG), and are consistently employed in our analysis below. The constant fertility assumption enables one to accurately determine and measure the extent of population change, caused by X-factor(s), keeping fertility rates fixed throughout the projection period (Lomax, 2017). The other demographic components (mortality and net-migration) will behave normally with constant fertility. For the Pacific, assumptions for mortality are specified in terms of life expectancy at birth. According to the UNFPA (2014), life expectancy in the region is set to increase by nearly 4 years in the next 20 years and the speed of this transition will become faster. This has been largely driven by the decrease in early life mortality and improvements in health care systems that have enabled the treatment of specific diseases.

On the contrary, international migration is most difficult to project as people's movement due to changing economic, political, social, and environmental factors vary. Most Pacific countries in our sample experience limited migration and therefore its impact is likely to be weak. Thus, adopting the assumption of low and constant migration throughout the projection period (except for Tonga and Samoa) is not unacceptable. Furthermore, when countries reach their replacement level fertility, a population shock will be more pronounced. In the Pacific, Fiji is now in this situation, but low populations remain a problem for development because this has 


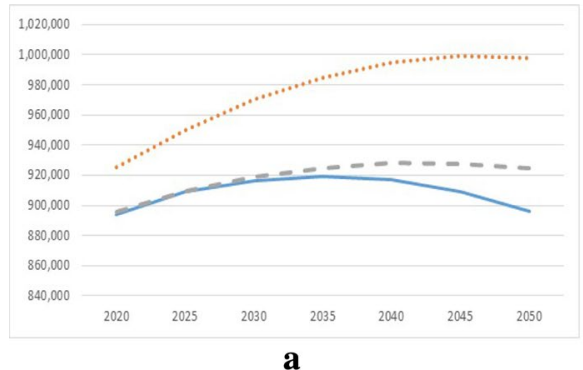

$\mathbf{a}$
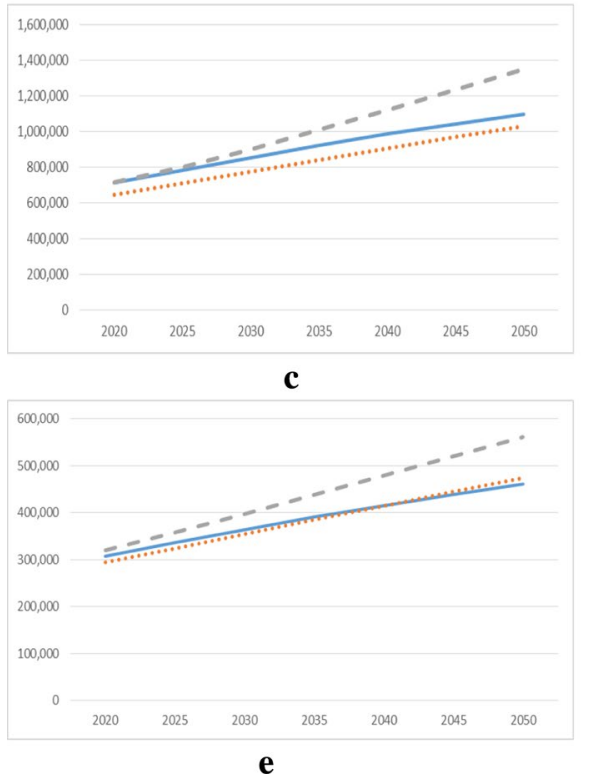

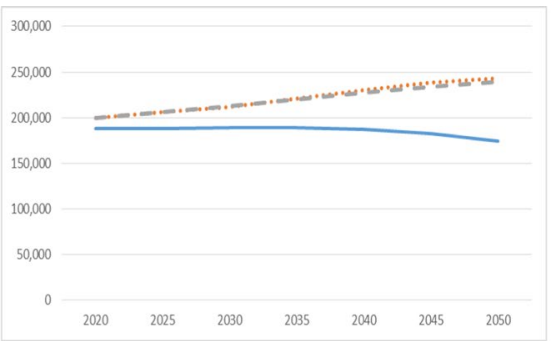

b
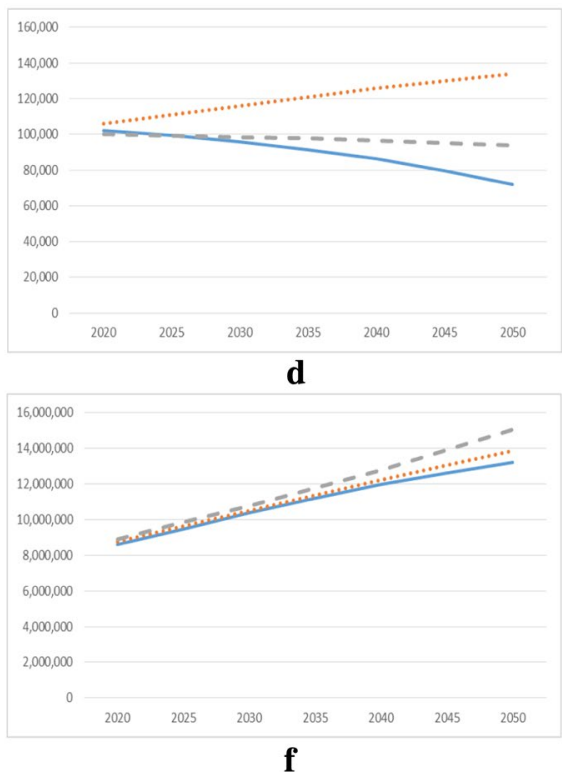

Fig. 2 a Fiji Population (2020-2050). b Samoa Population (2020-2050). c Solomon Islands Population (2020-2050). d Tonga Population (2020-2050). e Vanuatu Population (2020-2050). f Papua New Guinea's (2020-2050)

huge implications on the labour force, innovation, and productivity. The following provides insights into population dynamics, pre-and-post COVID19.

\section{Results: pre-COVID population projections (2020-2050)}

The pre-COVID19 projections against that of UNPD's and SPC's projections are presented in Fig. 2a-f. The SPC and ours are based on the CCM methodology, while the UNPD has used Bayesian Probabilistic Projections. Since SPC only has projections until 2050, and the UNPD has recently revised theirs, for consistency, we stick to 2050 as a common end period in our sample. The red dotted lines represent UNPD's projection, dashed lines are SPC's and the solid lines are our projections.

Figure $2 \mathrm{a}-\mathrm{f}$ shows that the projections are not largely different, particularly for Vanuatu, Solomon Islands, and PNG. However, our projections are closer to the 
SPC's projections and show that Fiji, Tonga, and Samoa will experience population decline from 2030 onward. For other countries (with high fertility rates and limited migration), the projections are similar to UNPDs. Despite the differences, they indicate alarming trends in Fiji, Tonga, and Samoa. The differences relate to the time at which each country is assumed to reach replacement level fertility. The literature suggests that this is likely to happen in 2045, details in Gubhaju and Moriki (2003). Further to that, Tonga and Samoa do experience a massive annual outflow of the population. The same can be implied for mortality rates, where the future values can be estimated by the average growth rates of the past. For that reason, life expectancy in Samoa, Tonga and Fiji could have been potentially underestimated. However, the UNPD derives a wide range of trajectories for life expectancy, which are more robust and used in our analysis.

Nevertheless, the implications from these projections are that future population pyramids in the Pacific countries will become constricted whereby the elderly population will outweigh the young-aged. There will be an increase in the number of retirees who will live longer but the problem that lies on the horizon is too few births. This will negatively impact the labour force, economic growth, and dependency of the old age population. The pressure would also be felt by those still in the labour force to provide support to senior citizens. This would also strain the government's resources and welfare schemes. The dependency ratio for PNG, Vanuatu and Solomon Islands is expected to be the lowest in the Pacific (UNPD, 2014).

\section{Potential impact of COVID19}

As is evident globally, high fatality rates could eventuate from the COVID19 pandemic in the Pacific as borders open. This can temporarily escalate the national mortality rate (even the age-specific mortality rates) but more permanently depress the population trajectories. We use two alternative scenarios to work out the relevant details for the Pacific region. However, since the fatality rates resulting from COVID19 are less certain, it can be estimated as follows. We conjecture that a nation's resilience rate (NRR) to COVID19 depends on two factors; resource endowment (proxied by real income) and health standards (proxied by life expectancy). These variables are assessed alongside the benchmark cases (indicated by variables with * in Eq. (2). So, the actual resilience rate is a weighted average of the relative income gap and differences in health services. The parameter $(\beta)$ measures the impact of each of the two variables on resilience rates. They can be called the relative weights (which can be calibrated) but for simplicity, we assume that they are equal at (0.5) each. Thus, both factors are equally important. Other researchers may innovate on NRR by including factors like population density and level of education etc.; which has implications on the spread and fatalities of COVID19.

Equation (3) determines the National Fatality Rate (NFR) as defined by the WHO (2020). This measures the actual number of deaths per number of affected persons. Using the two benchmark cases, we think that the NFR will vary from the benchmark cases at the rate of (1-NRR). That is, the higher the NRR, the lower would be the NFR. Thus, a country's position is measured by its relative distance from 
Table 2 Resilience and expected fatality rates of COVID19

\begin{tabular}{|c|c|c|c|c|}
\hline \multirow[t]{2}{*}{ Country } & \multicolumn{2}{|l|}{ Baseline: China } & \multicolumn{2}{|l|}{ Baseline: Italy } \\
\hline & $\begin{array}{l}\text { NRR } \\
\% \text { deviation from } \\
\text { baseline }\end{array}$ & $\begin{array}{l}\text { NFR } \\
\% \text { of infections }\end{array}$ & $\begin{array}{l}\text { NRR } \\
\% \text { deviation from } \\
\text { baseline }\end{array}$ & $\begin{array}{l}\text { NFR } \\
\% \text { of infections }\end{array}$ \\
\hline Fiji & -26.6 & 5.06 & -52.5 & 19.8 \\
\hline Vanuatu & -37.1 & 5.48 & -53.6 & 20.0 \\
\hline Tonga & -29.9 & 5.21 & -51.7 & 19.7 \\
\hline Samoa & -30.7 & 5.34 & -50.8 & 19.6 \\
\hline Solomon Isl & -44.0 & 5.76 & -54.0 & 20.0 \\
\hline PNG & -44.4 & 5.78 & -58.0 & 20.5 \\
\hline
\end{tabular}

Authors' calculation based on data from local and international sources

the benchmark levels of the two indicators. Finally, the Age-Specific Fatality Rate (ASFR, Eq. 4), is estimated as the post-COVID19 ASFR in the two baseline cases, adjusted for NRR. In short, Eq. (4) is an age-specific variant of (3) measuring the fatality rate.

$$
\begin{gathered}
N R R_{i}=\left[\beta_{1}\left[\frac{Y_{i}-Y^{*}}{Y^{*}}\right]+\beta_{2}\left[\frac{L E_{i}-L E^{*}}{L E^{*}}\right]\right] \times 100 \\
N F R_{i}=N F R^{*} \times\left[1-\frac{N R R_{i}}{100}\right] \\
A_{S F R_{i j}=A S F R^{*} \times\left[1-\frac{N R R_{i}}{100}\right]}
\end{gathered}
$$

Putting the above analytical model to data, we derive the estimates of expected resilience and expected fatality rates for each country in our sample (Table 2). Using China as a benchmark, the estimates indicate that at best, fatality rates could be $5 \%$ of those infected, with the highest rates expected for PNG and Solomon Islands. With Italy as the baseline, this could be as high as $20 \%$. This is quite serious and worse than the outcome of Italy itself.

Table 2 shows how the countries are positioned on the capacity scale (NRRs) with the alternative benchmarks and their expected average national fatality rates (NFRs) once the virus impacts these countries. In summary, it averages around 5-6\% (minimum) and 19\%-20\% (maximum). We underplay the impact of local initiatives (lockdowns and social distancing etc.) because these were also implemented in the baseline cases. Regional reports show that currently, the fatality rate is zero in the Pacific, but there remains a possibility of a second or third wave of COVID19. The island states have lower than average resilience reflected in their limited ability to deal with the crisis. Also, the direct and indirect effects of COVID19 on populations 
are expected to be significant. ${ }^{6}$ Against this backdrop, the estimated NFRs are not invalid and linearly feature in the population estimates (below) along with alternative scenarios. Table 2 shows that Fiji would have a fatality rate of just over 5\%, and the Solomon Islands and PNG (furthest away from the benchmark China) are expected to have a slightly higher rate $(5.8 \%)$. The regional average is estimated at $5.4 \%$ fatality of infections. If the situation is aggravated (like Italy), Tonga and Fiji will see a rise in fatality to about $20 \%$, similar to other countries.

The China-based scenario on NFR is not unexpected, especially if we account for the direct and indirect impacts of COVID19. Since the Pacific countries are capacity constrained, the impact of the virus is likely to be significant. In addition, these small economies will not be able to sustain a prolonged lock-down of their industries and economy because this can instigate another local crisis (economic recession), which can aggravate the situation. ${ }^{7}$ Against this backdrop, risks in all the Pacific countries' populations and therefore on livelihoods are high. This signals for well-planned COVID19 management systems and a coordination or implementation failure could spell a big disaster.

Table 4 in the "Appendix" is a quick reference to the age-specific benchmark indicators. Two observations are clear. First, the ASFRs are typical of the rates observed in other countries worldwide. Second, the aggregate fatality rate tends to be higher for the older population. However, real-time data show that the COVID19 cases in the Pacific countries are much lower than the world average, and the number of deaths due to COVID19 is low. This situation is likely to change dramatically when borders open for international travel and trade. From a population perspective, the indirect mortality impact due to COVID19 may be just as significant, if not larger than the direct impact of COVID19. Some analysis of potential indirect impacts is in Chen et al. (2020) and ADB (2020). The lifestyle change due to COVID19 may have a greater impact on mortality in these countries than COVID19 itself. From a theoretical perspective, the net loss resulting from the pandemic is likely to be huge, as societies are less economically oriented, mostly unemployed and have lost incomes and jobs.

Nonetheless, using the national resilience indicators computed above, we first find the following age-specific outcomes for the six countries. These are indicated in Fig. 3a-f below. The vertical axis represents the percentage of fatality and the horizontal axis shows age-specific intervals. The min and max represent the best and worst-case scenarios. The estimated fatality rates for all countries (except Fiji) show that people below the age of 50 are relatively safe. Once 50 years is reached, fatality starts to become significant. For Fiji, this starts at the age of 60 (possibly due to relatively better economy and medical services). We also find that for all other countries, the fatality risk escalates at 50 years on a moderate growth path. For Fiji,

\footnotetext{
6 Theoretically, the indirect effects are notably profound on populations. These include (but are not limited to) loss of incomes and employment, psychological effects, social disturbances, financial burdens, exclusions, fear and travel risk, cost of evacuation, isolation, vaccination, and safety of populations etc.

7 The Lowy Institute recently projects that the main thrust of economic reliance for the Pacific (tourism, migration, remittances, and aid) will be significantly affected. On average, these economies may experience a contraction of as much as $10 \%$ in their GDPs.
} 


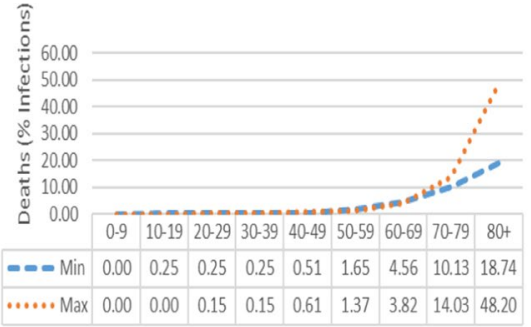

$\mathbf{a}$
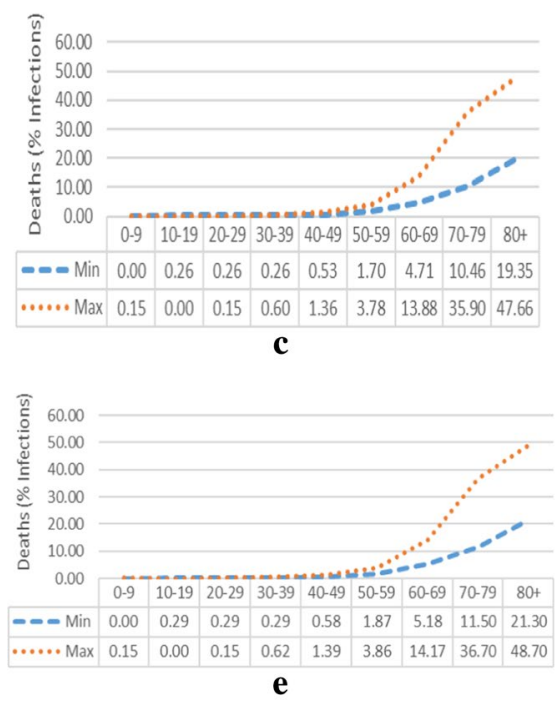

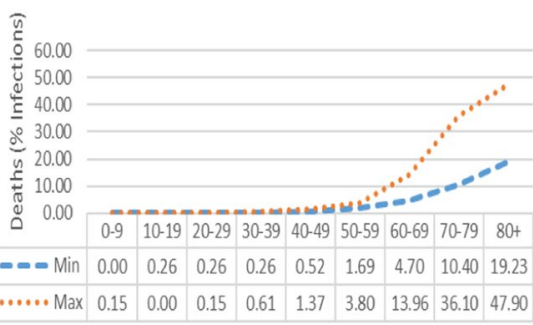

b
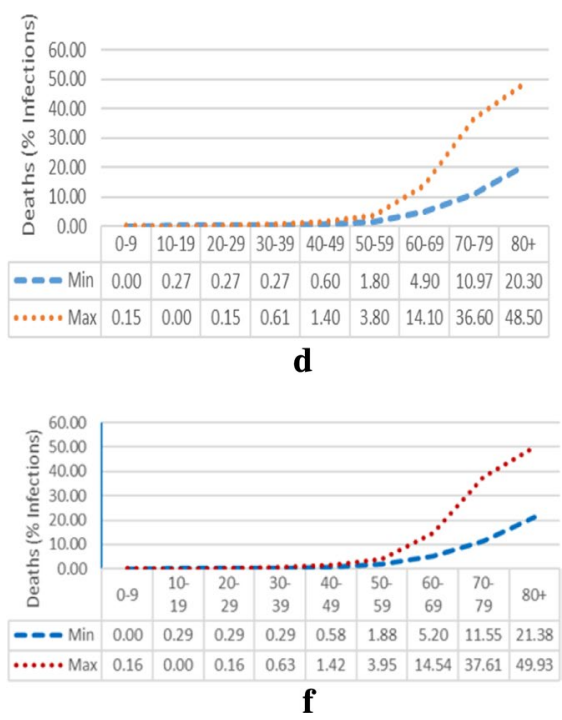

Fig. 3 Potential Effect of COVID19 on Age-Specific Fatality Rates (\% of the age-specific infected population)

the risk momentum is relatively steeper after $70,{ }^{8}$ reflecting Fiji's escalating risks in the longer-term. (Age structure data, reflecting our views, are included as population pyramids, in an "Appendix"). This could be because the older persons (over 60 years) are projected to grow to 170,500 by 2050 in Fiji with a constant annual growth rate. This contributes to a higher risk of mortality and population decline in the event of COVID19. Global evidence shows that older persons are less resistant to COVID19 compared to younger cohorts. However, for all countries, the fatality rate for those over 80 years is about $50 \%$. These are useful in projecting the post-COVID19 population estimates. The analysis is stretched to the ASFRs using indicators from China and Italy (Table 3) and Eq. (4). The results are summarised in Fig. 3a-f.

Based on Fig. 3a-f, the population variants are adjusted, and the aggregate populations are re-projected for the six countries. The comparative summary of the

\footnotetext{
${ }^{8}$ Currently, Fiji's older population is growing by 3000 people per year. This annual growth is expected to remain constant through to 2050 , thus contributing to higher risk, mortality rate and population decline in the future (Fiji Sun, 2018).
} 
$\mathbf{a}$
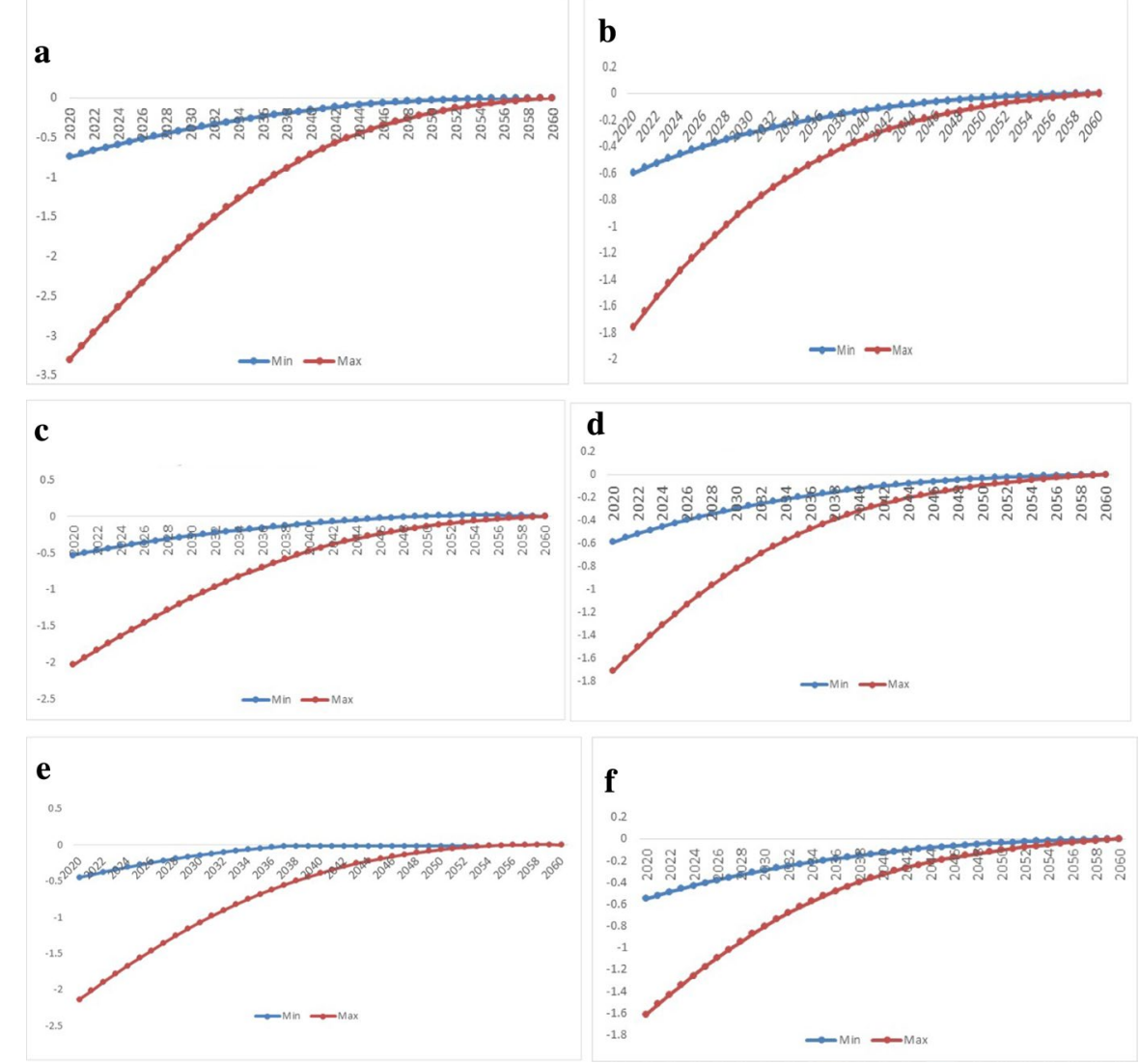

Fig. 4 Potential Effect of COVID19 on Pacific Populations (2020-2050) (\% deviation from baseline)

pre- and post-COVID19 projections with two alternative scenarios-min (Chinese benchmark) and the aggravated scenario (Italy benchmark) are given in Fig. 4a-f. The projections are made for the period 2020-2060. Our findings show that out of all, Fiji is most affected with an initial potential population decline of about $3.5 \%$ from the baseline. Other countries such as Tonga and Samoa are expected to experience an initial impact of about $-2 \%$ in the worst case. The remaining countries will have a slightly lower initial impact in the worst $(\max )$ baseline case. On the optimistic side, most countries, including Fiji will experience an impact of about $-0.6 \%$, initially. These effects will taper-off as time proceeds. The fastest catch-up (in the min case) is expected to be Tonga in about 18 years, followed by Samoa.

We find that most countries will revert to full-baseline situations by 2050. If the crisis is well managed, this could be even faster for all countries, except for the PNG and Solomon Islands (min case). Tonga, Samoa, and Fiji would be the interesting cases to monitor in the Pacific region, as each display out-laying responses to the effects of the virus. While Fiji has better medical services and higher incomes, its 
distance to replacement level fertility is shorter, implying lower population momentum. This will make population growth a huge challenge and result in a shock to its population. Figure $4 \mathrm{a}$ depicts this scenario. Tonga's high fertility and longer lifeexpectancy will ensure faster recovery to baseline if there are population disturbances, like COVID19. Samoa's reaction to the shock is similar to Tonga, but convergence is slower. This is because of relatively higher out-migration from Samoa, and it is further away from replacement level fertility. Other countries' speed of convergence to baseline will be about 35-40 years. This represents a huge sacrifice of welfare, productivity, incomes, and economic potential of the Pacific.

\section{Concluding comments}

Fiji, Tonga, and Vanuatu top the list of Pacific countries on the shift of the population towards older age (above 40 years). The increase in median age indicates that society is ageing and thereby will be more prone to illness and less resistant to viruses like Corona. The pre-COVID19 population growth rates show positive population growth in all PICs except for Tonga in the first half, while in the second half, Fiji and Samoa are highly likely to experience negative population growth rates. These are like projections of the UNPD and SPC. Our estimates show that most Pacific countries will have higher fatalities in the later age-groups, and within these, Fiji will have a serious decline in the 70+ age range due to COVID19. Others will have a relatively younger-age risk profile. However, if the crisis is not wellmanaged, an expected loss of all affected population of about 5\% (best) or $20 \%$ (worst) is likely. The projections with possible effects of COVID19 show that most countries in the region will experience about a $0.5 \%$ initial decline in total population (best) and about 2\% decline (worst). Of these, Fiji is expected to be the most strongly impacted. Tonga stands out as the country that will reach convergence to baseline quickly. Samoa will also have a quick recovery following Tonga, but the complete convergence of all countries to their pre-COVID19 population's trajectories is expected to be by 2050 .

This paper shows important information on how the populations (and therefore other real variables) in these economies are likely to change in the short-medium term. There are a few implications for population policy. First, given low fatality and high out-migration in some countries, as well as lower rates of increase in life expectancy in some, a crisis like COVID19 can be costly. As such, we advise greater caution on population management in all countries. Fiji, which is closest to its replacement level fertility is at greater risk and therefore, crisis management should be implemented with acute seriousness. There is a dire need for people to take advisories seriously, and the temporal restrictions on the movement of people including a close association with those infected should be strictly restricted. Countries should implement a quick recovery plan to salvage their economies, industries, and livelihoods. There is also a need for more resources and funding, possibly through donor programs to prevent widespread disaster in the six countries, should there be evidence of COVID19. At this stage, Fiji and PNG 
need to react faster and with more innovative methods, keeping local conditions and culture in mind. This can also imply some stringent regulations and controls. We expect our research to enlighten the six countries of the looming calamity but accept that it suffers from the lack of actual ASFRs for each country. We, therefore, invite other studies to fill this gap with a better dataset.

\section{Appendix 1: Pacific population projections}

See Tables 3, 4 and 5.

Table 3 Population Projection for the Pacific, (2020-2050)

\begin{tabular}{lllllll}
\hline Year & Fiji & Samoa & Solomon Islands & Tonga & Vanuatu & PNG \\
\hline 2020 & 894,153 & 188,219 & 711,288 & 102,050 & 306,717 & $8,618,801$ \\
2025 & 908,904 & 188,400 & 781,647 & 99,309 & 335,721 & $9,497,229$ \\
2030 & 916,287 & 188,610 & 852,694 & 95,759 & 364,064 & $10,364,704$ \\
2035 & 919,281 & 188,678 & 922,506 & 91,505 & 391,203 & $11,200,524$ \\
2040 & 917,128 & 187,230 & 987,778 & 86,126 & 415,889 & $11,967,765$ \\
2045 & 909,276 & 182,343 & $1,044,806$ & 79,656 & 439,058 & $12,625,320$ \\
2050 & 896,376 & 174,534 & $1,098,380$ & 71,970 & 461,388 & $13,220,847$ \\
\hline
\end{tabular}

Source: Author's Computations (2020)

Table 4 UNPD Population Projection for the Pacific, (2020-2050)

\begin{tabular}{lllcccr}
\hline Year & Fiji & Samoa & Solomon Islands & Tonga & Vanuatu & PNG \\
\hline 2020 & 925,000 & 200,000 & 647,000 & 111,000 & 294,000 & $8,756,000$ \\
2025 & 950,000 & 206,000 & 709,000 & 116,000 & 324,000 & $9,614,000$ \\
2030 & 970,000 & 212,000 & 773,000 & 121,000 & 354,000 & $10,487,000$ \\
2035 & 985,000 & 221,000 & 839,000 & 127,000 & 385,000 & $11,362,000$ \\
2040 & 995,000 & 230,000 & 905,000 & 132,000 & 415,000 & $12,224,000$ \\
2045 & 999,000 & 238,000 & 970,000 & 136,000 & 445,000 & $13,064,000$ \\
2050 & 998,000 & 243,000 & $1,033,000$ & 140,000 & 475,000 & $13,871,000$ \\
\hline
\end{tabular}

Source: United Nations Population Division (2014)

Table 5 SPC Population Projection for the Pacific, (2020-2050)

\begin{tabular}{lllcllr}
\hline Year & Fiji & Samoa & Solomon Islands & Tonga & Vanuatu & PNG \\
\hline 2020 & 895,400 & 199,300 & 714,800 & 100,000 & 319,500 & $8,901,200$ \\
2025 & 909,300 & 205,700 & 802,800 & 99,200 & 357,900 & $9,846,300$ \\
2030 & 918,700 & 212,700 & 902,300 & 98,400 & 397,300 & $10,790,800$ \\
2035 & 924,900 & 220,300 & $1,010,900$ & 97,700 & 437,900 & $11,757,100$ \\
2040 & 927,900 & 227,800 & $1,123,600$ & 96,700 & 479,500 & $12,798,600$ \\
2045 & 927,700 & 234,200 & $1,237,200$ & 95,300 & 521,100 & $13,915,200$ \\
2050 & 924,700 & 239,100 & $1,351,600$ & 93,600 & 561,900 & $15,057,600$ \\
\hline
\end{tabular}

Source: Secretariat of the Pacific Community (2016) 


\section{Appendix 2}

See Table 6 and Fig. 5.

Table 6 Baseline Indicators for Analysis

\begin{tabular}{lll}
\hline Indicators & China $(\%)$ & Italy $(\%)$ \\
\hline Aggregate Fatality Rate & 3.9 & 13 \\
$80+$ & 14.80 & 31.60 \\
$70-79$ & 8.0 & 23.80 \\
$60-69$ & 3.60 & 9.20 \\
$50-59$ & 1.30 & 2.50 \\
$40-49$ & 0.40 & 0.90 \\
$30-39$ & 0.20 & 0.40 \\
$20-29$ & 0.20 & 0.10 \\
$10-19$ & 0.20 & 0 \\
$0-9$ & 0 & 0.10 \\
\hline
\end{tabular}

Source: The Worldometer (China), and Statista (Italy), 2020 
Fiji

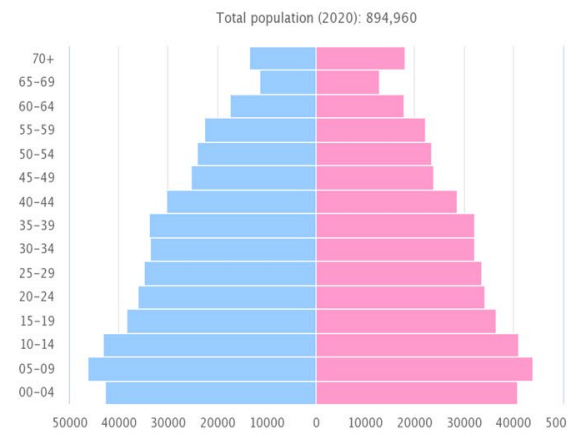

Samoa

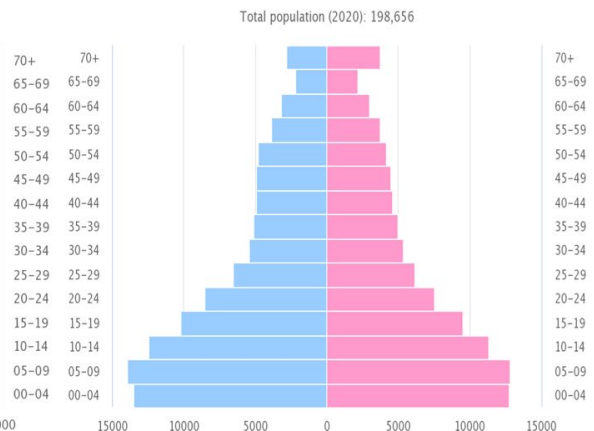

Tonga

Total population (2020): 99,775

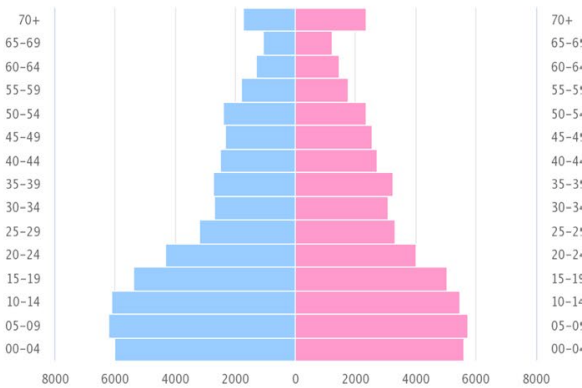

Papua New Guinea

Total population (2020): 8,934,474

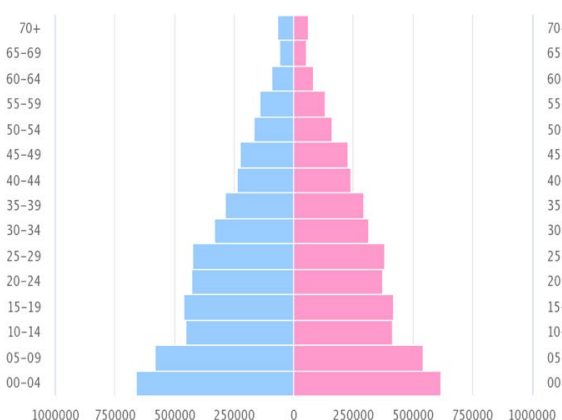

Fig. 5 Population pyramid for select pacific Island countries. Source: Statistics for Development Division (2020)

\section{References}

Asian Development Bank (2017). Pacific Approach 2016-2020. Mandaluyong City: ADB Photo Library. Asian Development Bank. (2020). The Economic Impact of the COVID-19 Outbreak on Developing Asia, ADB Briefs No 128. ADB. 
Australian Bureau of Statistics. (2018, November 21). Population Projections, Australia, 2017 (base) 2066. Retrieved from ABS: https://www.abs.gov.au/AUSSTATS/abs@.nsf/mf/3222.0

Beer, J. (2000). Dealing with uncertainty in population forecasting. Statistics Netherlands Department of population.

Blue, L., \& Espendshade, J. (2011). Population momentum across the demographic transition. Population Development Review, 37(4), 721-747.

Chen, K., Wang, M., Huang, C., Kinney, P. L., \& Anastas, P. T. (2020). Air pollution reduction and mortality benefit during the COVID-19 outbreak in China. The Lancet Planetary Health.

Choi, S. (2010). Application of the Cohort Component Model to Development of Local Population Projections. Southern California Association of Governments.

Congdon Fors, H. (2014). Do Island states have better institution? Journal of Comparative Economics, 42(1), 34-60.

Department of Economic and Social Affairs. (2002). Completing the Fertility Transition. Retrieved from United Nations Population Division: http://www.un.org/en/development/desa/population/publicatio ns/fertility/fertility-transition.shtml

Department of Economic and Social Affairs; Population Division. (2017). World Population Prospects. The 2017 Revision. Methodology of the United Nations Population Estimates and Projections. New York: United Nations.

Dion, P. (2012). Evaluating Population Projections: Insights from a Review made at Statistics Canada. Population Association of America.

Ellis, W. (2020, May 31). COVID19 and Its Impact on Pacific Island States. Retrieved from SPC: https:// www.spc.int/updates/blog/2020/06/covid-19-and-its-impact-on-pacific-island-states

Futures Group International. (2005). Computer Programs for Examining the Socioeconomic Impacts of Population Growth. Futures Group International.

Gani, A. (1999). An economic analysis of factors influencing fertility in the Pacific island countries. International Journal of Social Economics, 26(1-3), 345-353.

Gans, d. . (1999). Population forecasting 1895-1945: The transition to modernity. Kluwer Academic.

George, M., Smith, S., Swanson, D., \& Tayman, J. (2004). Population projections. Elsevier Academic Press.

Gubhaju, B., \& Moriki-Durand, Y. (2003). Fertility levels and trends in the Asian and Pacific Region. Emerging Social Issues Division.

Health Policy Plus. (2015). SPECTRUM. Retrieved from Health Policy Plus. Better Policy for Better Health: http://www.healthpolicyplus.com/spectrum.cfm

Heilig, G., Buettner, T., Li, N., Gerland, P., Alkema, L., Chunn, J., \& Raftery, A. (2010). Future population trends found to be highly uncertain in Least Developed Countries. National Institutes of Health.

Hou, X., Anderson, I., \& Burton-Mckenzie, E.-J. (2016). Pacific possible: Health and non-communicable diseases. The World Bank.

Johnson, S. (2020). A changing nation: Population projections under alternative immigration scenarios. U.S. Census Bureau.

Jones, C. (1995). R and D-based models of economic growth. Journal of Political Economy, 103(4), $759-784$.

Kamunya, M. (2010). Primary school-age population projections for countries in Central Province, Kenya. University of Nairobi.

Keilman, N. (1998). How accurate are the United Nations World Population Projections? Population and Development Review, 24, 15-41.

Keyfitz, N. (1972). On future population. Journal of the American Statistical Association, 67(338), $347-363$.

Kodiko, H. (2011). Sub-National Projection Methods: Application to the countries in the former Nyanza Province, Kenya. Population Studies and Research Institute

Lal, S., and Singh, R. (2019). Empirical Analysis of Fertility: A Cross-Country Study of the Pacific Islands. Retrieved from School of Economics: https://www.usp.ac.fj/fileadmin/files/schools/ssed/ economics/working_papers/2019/Working_Paper_-_Empirical_Analysis_of_Fertility_A_CrossCountry_Study_of_the_Pacific_Islands.pdf

Li, N., \& Tuljapurkar, S. (1999). Population momentum for gradual demographic transitions. Population Studies, 53, 255-262. 
Lomax, N. (2017). Variant population projections are more important than ever. Retrieved from Population Geography: https://popgeog.org/2017/11/30/variant-population-projections-are-moreimportant-than-ever/

Morgan, P. (2003). Is low fertility a twenty-first-century demographic crisis? PMC, 40(4), 589-603.

Murdock, S., Hamm, R., Voss, P., and Pecotte, B. (1991). Evaluating small-area population projections. Journal of the American Planning Association, 57(4), 432-443. Retrieved from Research Gate.

Narsey, W., Robertson, A., Prasad, B., \& Seniloli, K. (2009). Population and Development in the Pacific Islands. WordWorks Fiji.

National Center for Education Statistics. (2014). Projections of Education to 2022. US Department of Education.

National Records of Scotland. (2006). What are Variant Projections and Why are They Needed? Edinburgh: A National Statistics publication. Retrieved from National Records of Scotland.

Raftery, A., Alkema, L., \& Gerland, P. (2014). Bayesian population projections for the United Nations. Statistical Science, 29(1), 58-68.

Samir, K., Barakat, B., Goujon, A., Skirbekk, V., Sanderson, W., \& Lutz, W. (2010). Projection of populations by level of educational attainment, age, and sex for 120 countries for 2005-2050. Demographic Research, 22(15), 383-472.

Sawyer, C., \& Bassarsky, L. (2016). Subnational population projections. US Census Bureau.

Secretariat of the Pacific Community. (2016). Population Projections by Pacific Island Countries. Retrieved from Prism: https://prism.spc.int/

Smith, S., Swanson, D., \& Tayman, J. (2001). State and local population projections: Methodology and analysis. Kluwer Academic/Plenum Publishers.

Statista. (2020). Coronavirus (COVID-19) death rate in Italy by age group. Retrieved from Statista: https://www.statista.com/statistics/1106372/coronavirus-death-rate-by-age-group-italy/

Stats NZ. (2017). Population projections tables. Retrieved from Stats NZ: http://archive.stats.govt.nz/ browse_for_stats/population/estimates_and_projections/NationalPopulationProjections_HOTP2 016.aspx

The United Nations; Department of Economic and Social Affairs; Population Division. (2004). World Population Prospects. The 2002 Revision. Volume III: Analytical Report. New York: United Nations.

The World Bank. (2017, May 13). Fertility rate, total (births per woman). Retrieved from World Development Indicators: https://data.worldbank.org/indicator/SP.DYN.TFRT.IN

Tisdell, C. (2014). The MIRAB Model of Small Island Economies in the Pacific and their Security Issues: Revised Version. Social Economics, Policy and Development Working Papers 165087, University of Queensland.

U.S Ministry of Education. (2009). Projection of Education Statistics. National Centre for Education Statistics.

UN Population Division. (2015). World Population Prospects: The 2015 Revision, Methodology of the United Nations Population Estimates and Projections. New York: Working Paper No. ESA/P/ WP. 242.

United Nations. (2019). Sustainable Development Outlook - Gathering Storms and Silver Linings. UN Publication.

United Nations Department of Economic and Social Affairs. (2015). World Population Prospects The 2015 Revision. United Nations Population Division.

United Nations Population Division. (2017). World Population Prospects. The 2017 Revision highlights. New York: Department of Economic and Social Affairs.

United Nations Population Fund. (2014). Population ageing in the Pacific Islands: a situation analysis. Suva: UNFPA.

WHO. (2020). Coronavirus disease 2019 (COVID-19) Situation Report-45. WHO.

Wilson, T. (2011). A Review of Sub-Regional Population Projection Methods. Queensland Centre.

Wilson, T., \& Rees, P. (2005). Recent developments in population projection methodology: A review. Population, Space and Place, 11(5), 337-360.

Worldometer. (2020, April 16). Age, Sex, Existing Conditions of COVID-19 Cases and Deaths. Retrieved from Worldometer: https://www.worldometers.info/coronavirus/coronavirus-age-sex-demographics. 
Publisher's Note Springer Nature remains neutral with regard to jurisdictional claims in published maps and institutional affiliations. 